\title{
Prediction of Required Specification for the Development of Future Gasoline Turbo Engine Standards through Time Series Analysis
}

\author{
SeungHyun Chung ${ }^{1}$, JoonYoung Park ${ }^{2 *}$ and JinYeong $\mathrm{Um}^{3^{*}}$ \\ ${ }^{1}$ Student, 04620 Dept. Industrial Engineering, Dongguk Univ., 30, Pildong-ro 1-gil, \\ Jung-gu, Seoul, Korea \\ ${ }^{2}$ Professor, 04620 Dept. Industrial Engineering, Dongguk Univ., 30, Pildong-ro 1-gil, \\ Jung-gu, Seoul, Korea \\ ${ }^{3}$ Professor, 04620 Dept. of Computer Science \& Engineering, Dongguk Univ. 30, \\ Pildong-ro 1-gil, Jung-gu, Seoul, Korea \\ ${ }^{1}$ shchung@dongguk.edu, ${ }^{2}$ jypark@dongguk.edu, ${ }^{3}$ mog07@dongguk.edu
}

\begin{abstract}
Environmental regulations have been tightened since Volkswagen's diesel gates. In order to cope with environmental regulations, eco-friendly cars should be developed, but due to the high price, it is difficult to be accepted by all consumers. In addition, as customer needs diversify, the product life cycle is shortening. Manufacturers need to innovate their processes to diversify their products and reduce lead times. This paper aims to predict long-term future engine torque in order to secure development efficiency and competitiveness of internal combustion engines, which are the major components of automobiles. Sales data for 20 years from 1998 to 2017 were used, with weights based on sales volume. Based on the above data, time series analysis was conducted using three methods, MA, ARIMA, and Fitted Regression. The results of the prediction for each segment were derived, and the engine can be used to plan the engine with appropriate torque.
\end{abstract}

Keywords: Data mining, Time series analysis, Integrated product planning, Market needs forecasting

\section{Introduction}

Since the 2015 'diesel gate', Volkswagen, the world's second-largest automaker group, raised the need for tightening environmental regulations worldwide [1]. Questions have been raised about the eco-friendliness of diesel engines, known as clean diesel, and some European cities are planning to prohibit the entry of vehicles with older diesel engines [2]. For that reason, as shown in [Figure 1], regulations on automobile emissions and greenhouse gases are tightening worldwide. In particular, the average regulation of makers' greenhouse gas emissions will be strengthened to $95 \mathrm{~g} / \mathrm{km}$ in Europe in 2021, and $97 \mathrm{~g} / \mathrm{km}$ in Korea in 2020 and $99 \mathrm{~g} / \mathrm{km}$ in the US and Canada [3].

In order to meet the environmental regulations should be developed for eco-friendly vehicles such as electric cars or hybrid cars, however, it is a difficult situation although acceptable to all consumers because of high prices. In addition, as customer needs diversify, the product life

Article history:

Received (February 5, 2020), Review Result (March 9, 2020), Accepted (April 12, 2020) 
cycle is shortening. Manufacturers need to innovate their processes to diversify their products and reduce lead times.

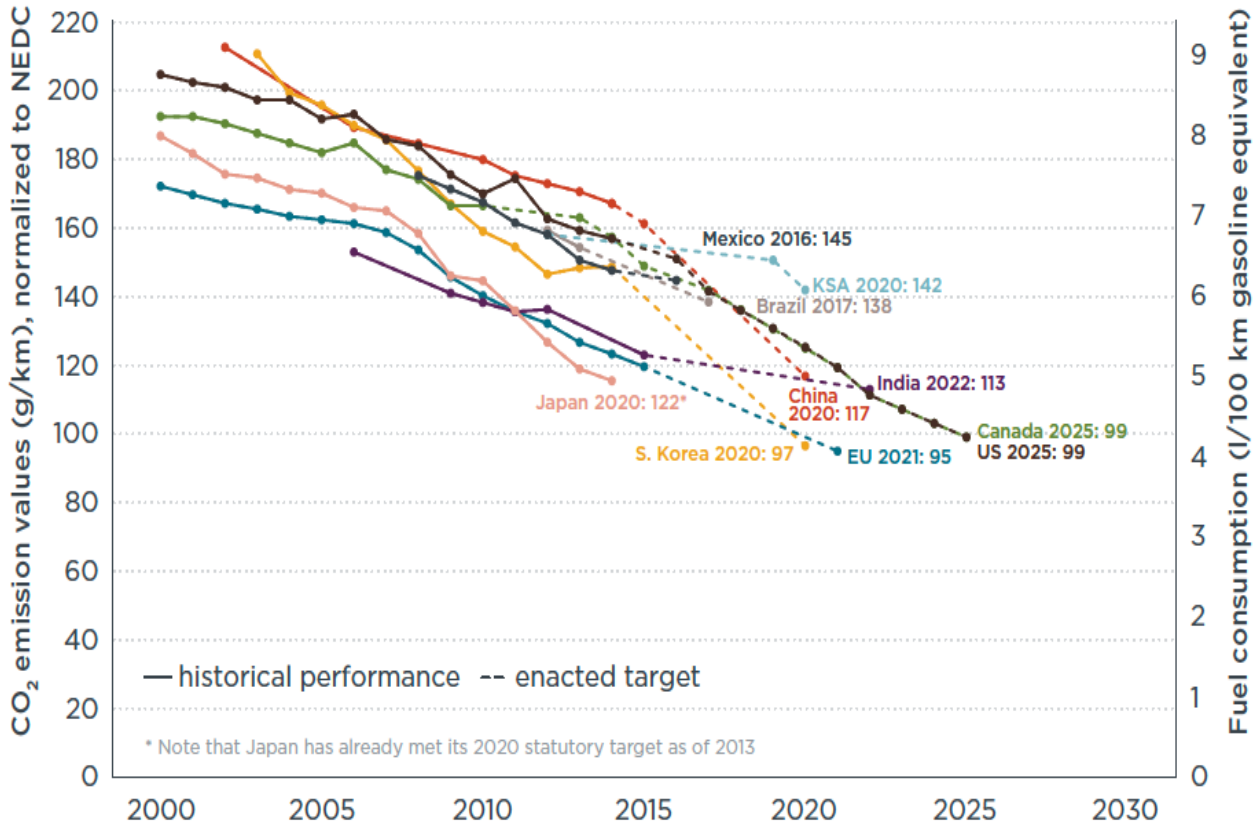

Figure 1. Historical fleet $\mathrm{CO} 2$ emissions performance and current standards $(\mathrm{gCO} / \mathrm{km})$ for $\mathrm{PC}$

From this point of view, to reduce development complexity in developing new products, it is necessary to consider ways to reduce development load and component development costs. Modularization is one of the methods. Toyota, a Japanese automaker, announced a Dynamic Force engine that replaces the entire engine lineup [4]. The engine uses the same cylinder design for all engine lineups from small to large in modular design while improving performance and fuel economy through structural optimization. Along with the mass production of the engine, Range Extended Electric Vehicle is being developed to make the parts in mass production possible [5]. In addition, many mass production car brands are considering ways to improve fuel efficiency while sharing existing powertrains [6].

This paper aims to predict long-term future engine torque in order to secure development efficiency and competitiveness of internal combustion engines, which are the major components of automobiles. The structure of this paper is as follows. In Chapter 2, explains the results, characteristics, and variables of data collection for analysis. Chapter 3 lists and describes the results of the analysis. Finally, Chapter 4 presents the limitations of the study and future research directions.

\section{Data collection and purification}

The analysis focused on the North American market, where gasoline sales are highest. The [Figure 2] below shows a breakdown of the type of gasoline engine intake analysis at IHS Company, starting from 2021 the share of turbo engines can see beyond the weight of the naturally aspirated engine [7]. 


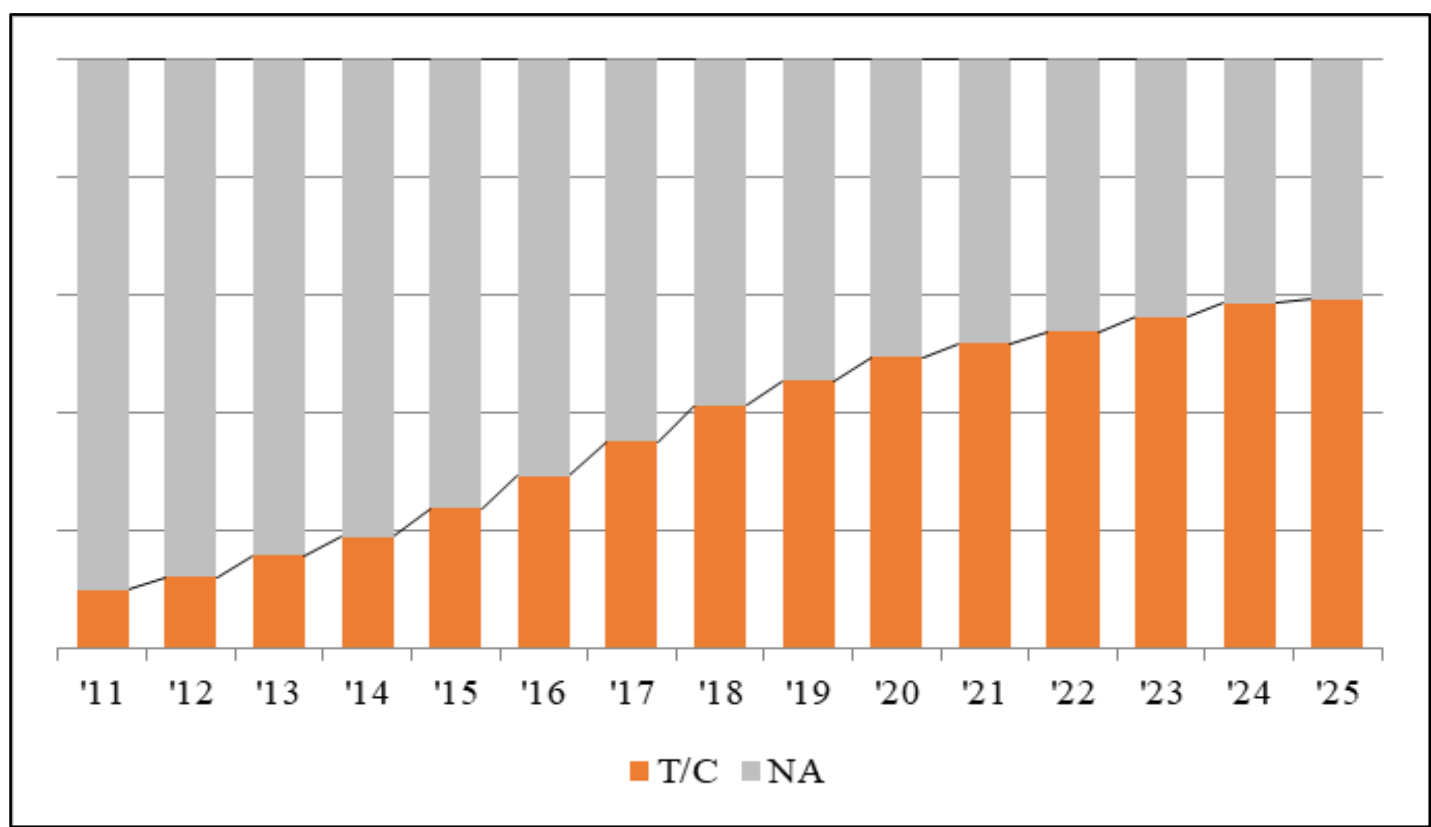

Figure 2. Production forecast by type of gasoline engine

Variables were selected through interviews with senior industry experts. Analytical data were taken from JATO's data [8]. North American market-based sales data for 20 years from 1998 to 2017 were used, with weights based on sales volume. Data, or the value is empty, the purification is needed in advance because it is dirty, such as outliers exist [9]. The number of final data after the refining operation is 5,555 cases, and the variable composition of the data used is shown in [Table 1] below.

Table 1. Composition of data

\begin{tabular}{|c|c|c|}
\hline Variable & Variable Description & Example \\
\hline Make group & Car maker name & BMW \\
\hline Vehicle Segment & Global vehicle segment & B-SUV \\
\hline Kerb weight & Car weight for certification test & $1650 \mathrm{~kg}$ \\
\hline Max torque & Engine torque (power) & $500 \mathrm{Nm}$ \\
\hline Yr98 Yr17 & Sales volume by year for each vehicle & 1,881 \\
\hline
\end{tabular}

Torque is an important factor in the performance of the vehicle, but it is directly proportional to the weight of the vehicle. This is because high torques are required when moving heavy vehicles, and low torques when moving relatively light vehicles. Considering this point, the final predicted variable is defined in Equation 1 below.

$$
\frac{T Q}{K W}=\frac{\operatorname{Max} \operatorname{Torque}(\mathrm{Nm})}{\operatorname{Kerb} W \operatorname{Wight}(\mathrm{kg})}
$$

By predicting the above values, you can determine if you are demanding a leisurely performance for each year. Depending on the weight of the vehicle to be built in the future, it is also possible to construct an engine family with an appropriate peak torque. 


\section{Result of data analysis}

Based on the above data, time series analysis was conducted using three methods, MA, ARIMA, and Fitted Regression, and the results are shown in Table 2 below. MA and ARIMA conservatively reflect past trends, and Fitted Regression features dynamic follow-up over other models.

Table 2. Result of TQ/KW future prediction

\begin{tabular}{|c|c|c|c|c|c|}
\hline \multirow{2}{*}{ Vehicle Segment } & \multirow{2}{*}{ TQ/KW tendency } & TQ/KW of 2017 & \multicolumn{3}{|c|}{ TQ/KW of 2030 } \\
\cline { 4 - 6 } & Decrease & 0.195 & 0.190 & 0.189 & 0.176 \\
\hline C-SUV & Increase & 0.206 & 0.200 & 0.204 & 0.203 \\
\hline D-SUV & Decrease after & 0.213 & 0.221 & 0.224 & 0.190 \\
\hline C-Sedan & upward & 0.227 & 0.231 & 0.232 & 0.237 \\
\hline D-Sedan & Stay after rise & 0.272 & 0.264 & 0.254 & 0.297 \\
\hline E-Sedan & Stay after rise & & & \\
\hline
\end{tabular}

The data reflect each vehicle sales as a weight. Details of the prediction result for each vehicle segment are as follows.

[Figure 3] shows a C-SUV's TQ / KW is decreasing significantly compared to 2006, and all three models are expected to be lower than before.

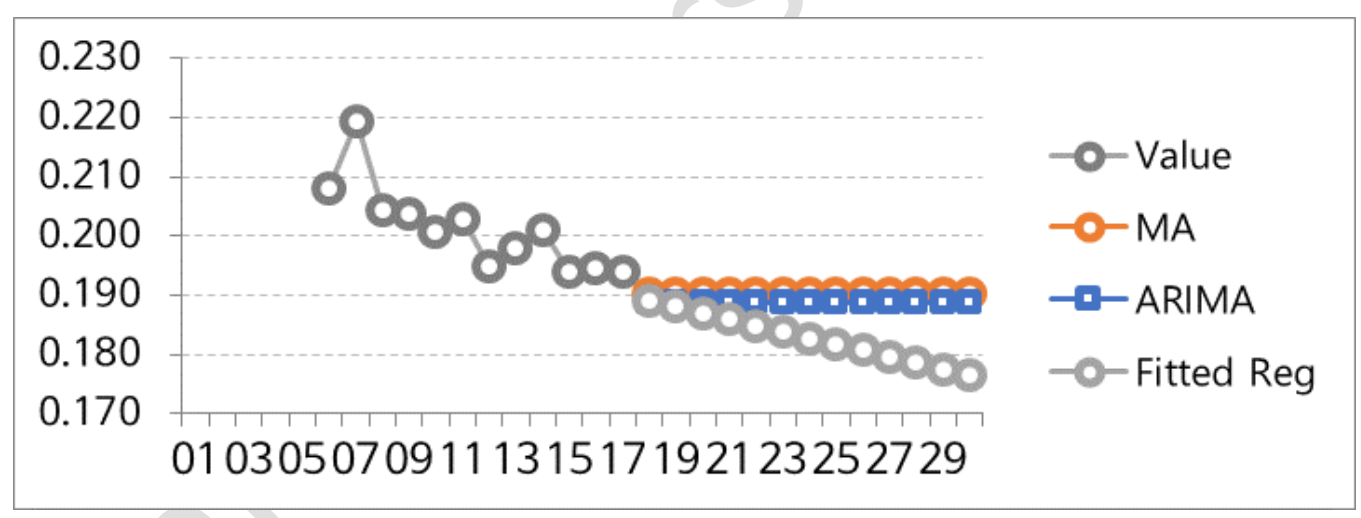

Figure 3. C-SUV's TQ/KW forecast

[Figure 4] shows the TQ / KW forecast of D-SUV, which is maintained after the sharp rise in TQ / KW from 2006. Since the subsequent fluctuations are not large, the prediction results of all three models are similar. 


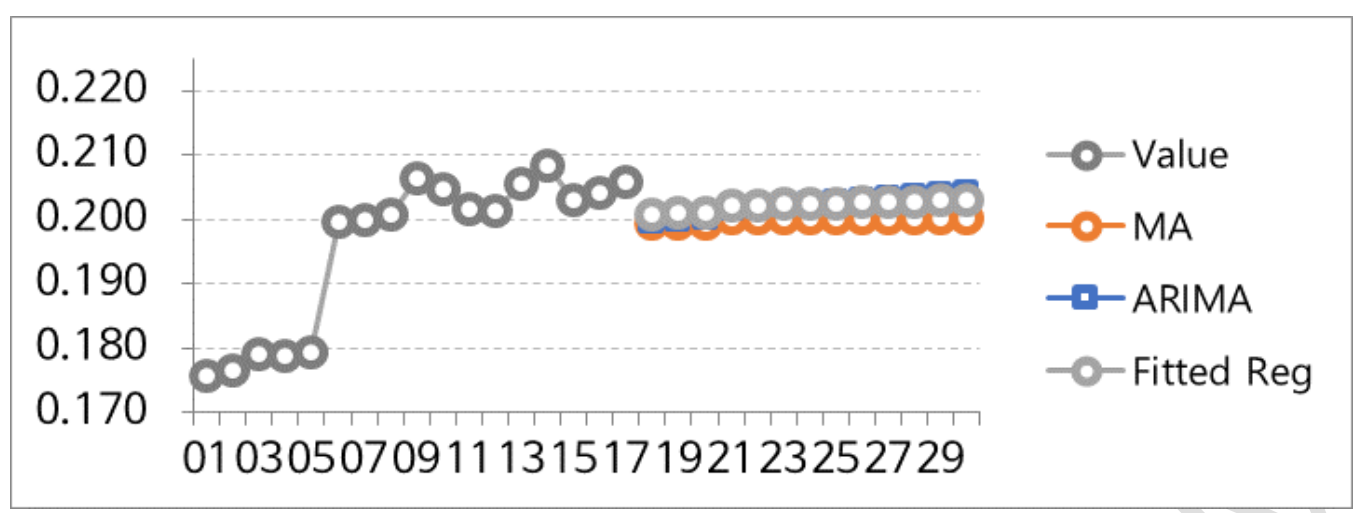

Figure 4. D-SUV's TQ/KW forecast

[Figure 5] shows C-Sedan's TQ / KW forecast, which remained until 2017 after a sharp rise, with values ranging from 0.21 to 0.22 . The value was predicted to decrease rapidly to 0.19 , and MA and ARIMA predicted a slight increase.

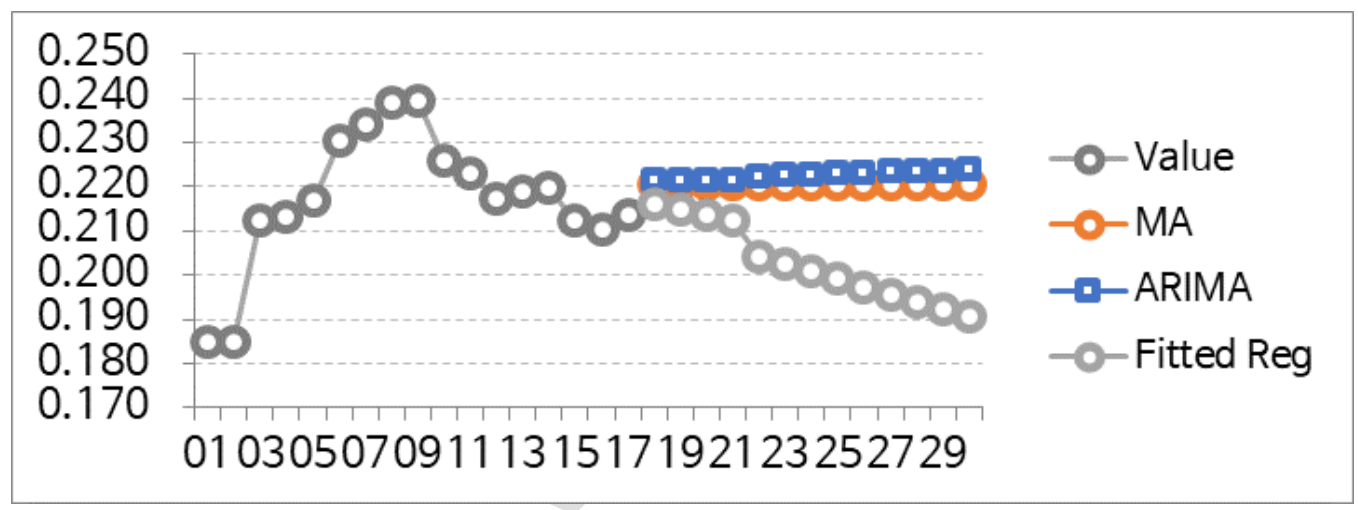

Figure 5. C-Sedan's TQ/KW forecast

[Figure 6] above shows D-Sedan's TQ / KW forecast. After a sharp rise in 2004, it rises and falls. The prediction results were $0.231 \sim 0.237$ for all three models, with the smallest difference between the models.

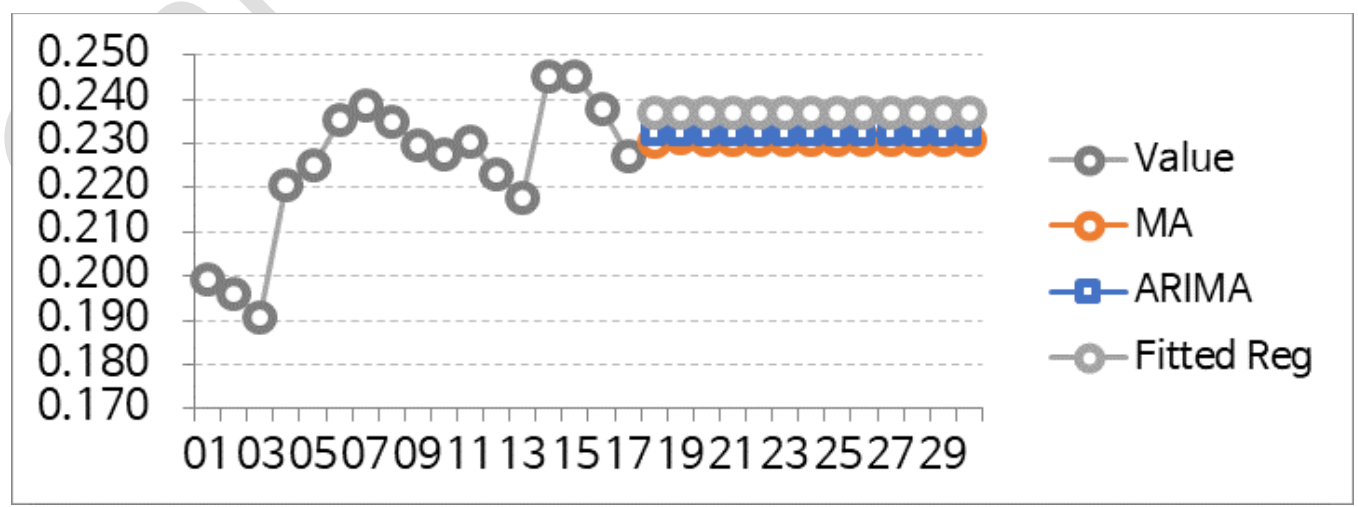

Figure 6. D-Sedan's TQ/KW forecast 
[Figure 7] above shows E-Sedan's TQ / KW forecast, which shows that historical data is maintained after a significant rise and fall. The MA and ARIMA forecasts predicted a slight decline. Fitted Reg expects to rise after a period of time.

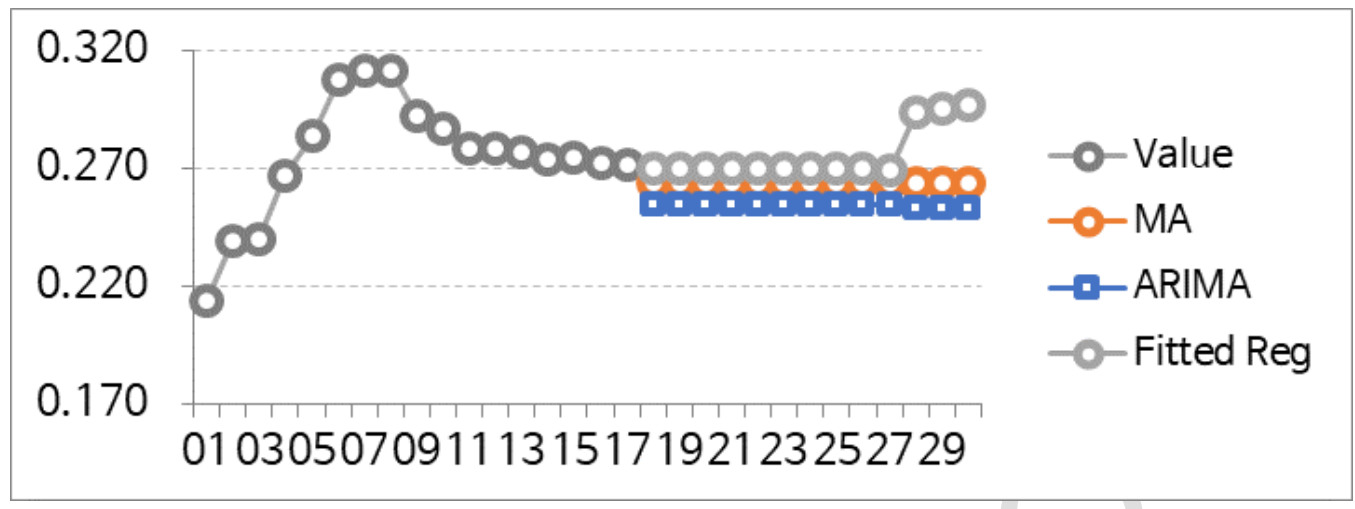

Figure 7. E-Sedan's TQ/KW forecast

In some analysis results, Fitted Regression and other prediction results may be different. In particular, in the case of C-sedan and C-SUV, the Fitted Regression model seems to follow more volatility. In this case, it is necessary to try to identify other factors in selecting a predictive model.

\section{Conclusion}

In this paper, the torque of the future gasoline turbo engine is estimated using historical data. The maximum torque to the kerb weight is predicted based on the global segment, and when the torque value to be exerted by the engine is determined, design freedom is reduced by one step, which is advantageous in optimizing other values. By specifying predictors as torque to kerb weight, you can determine the level of performance a consumer requires.

The necessity of this study is as follows. When deciding on a specification in the existing product planning, the method of identifying consumer needs through interviews and making policy decisions was mainly used. For example, Mercedes-Benz, in particular, has a high maximum torque value unlike most mass-produced brands, which is believed to be based on the policy decision that Mercedes' performance is priority. However, in this study, we focused on understanding the torque level that consumers prefer, using the maximum torque and kerb weight that have weighted sales data of past vehicles as weights. If the above data predicts torque to kerb weight after 10 years, it is possible to design a product that meets the needs of the consumer and to share the specifications of the components mounted on the product at the same time. In other words, it is possible to manufacture a part that is commonly used to cope with the future shorter product life cycle, it can be advantageous for development costs and guarantee. The limitation of this paper is that it could not refine the prediction result such as analyzing the event of the inflection point of the data and reflecting it as the weight. In the future, we will analyze the external factors that influence the powertrain specification and conduct correlation analysis.

\section{Acknowledgements}


This research was supported by Basic Science Research Program through the National Research Foundation of Korea (NRF) funded by the Ministry of Education (No.2017R1D1A1B03032736).

\section{References}

[1] Boretti A., The Future of the Internal Combustion Engine after "Diesel-Gate", SAE Technical Paper 2017-28, pp.1933, (2017) DOI:10.4271/2017-28-1933

[2] Möhner M., "Driving ban for diesel-powered vehicles in major cities: an appropriate penalty for exceeding the limit value for nitrogen dioxide?" Int Arch Occup Environ Health, vol.91, pp.373-376 (2018) DOI:10.1007/s00420-018-1297-4

[3] Z. Yang and A. Bandivadekar, "2017 global update light-duty vehicle greenhouse gas and fuel economy standards," ICCT, (2017)

[4] M. Hakariya, T. Toda, M. Sakai, "The new Toyota Inline 4-Cylinder 2.5L gasoline engine," SAE Technical Paper, (2017) DOI:10.4271/2017-01-1021

[5] E. Nakai, T. Goto, K. Ezumi, Y. Tsumura, K, Endou, Y. Kanda, T. Urushihara, M. Sueoka, and M. Hitomi, "Mazda motor corporation, mazda SKYACTIV-X 2.0L gasoline engine," 28 Aachener Kolloquium, October 7-9; Eurogress Aachen, Germany, (2019)

[6] https://s3.amazonaws.com/automotiveworld/webinars/18-11-07-Ricardo-Optimising-hybrid-vehicles-in-aworld-of-increasing-powertrain-complexity.pdf, (2018)

[7] IHS: IHS global production forecast, (2017)

[8] JATO Dynamics: JATO global car sales data, (2017)

[9] Berry and Michael J. A, "Data mining techniques: for marketing, sales, and customer relationship management 2nd ed.,"WILEY, pp.72-75. ISBN:0-471-47064-3, (2004) 
Prediction of Required Specification for the Development of Future Gasoline Turbo Engine Standards through Time Series Analysis

This page is empty by intention.

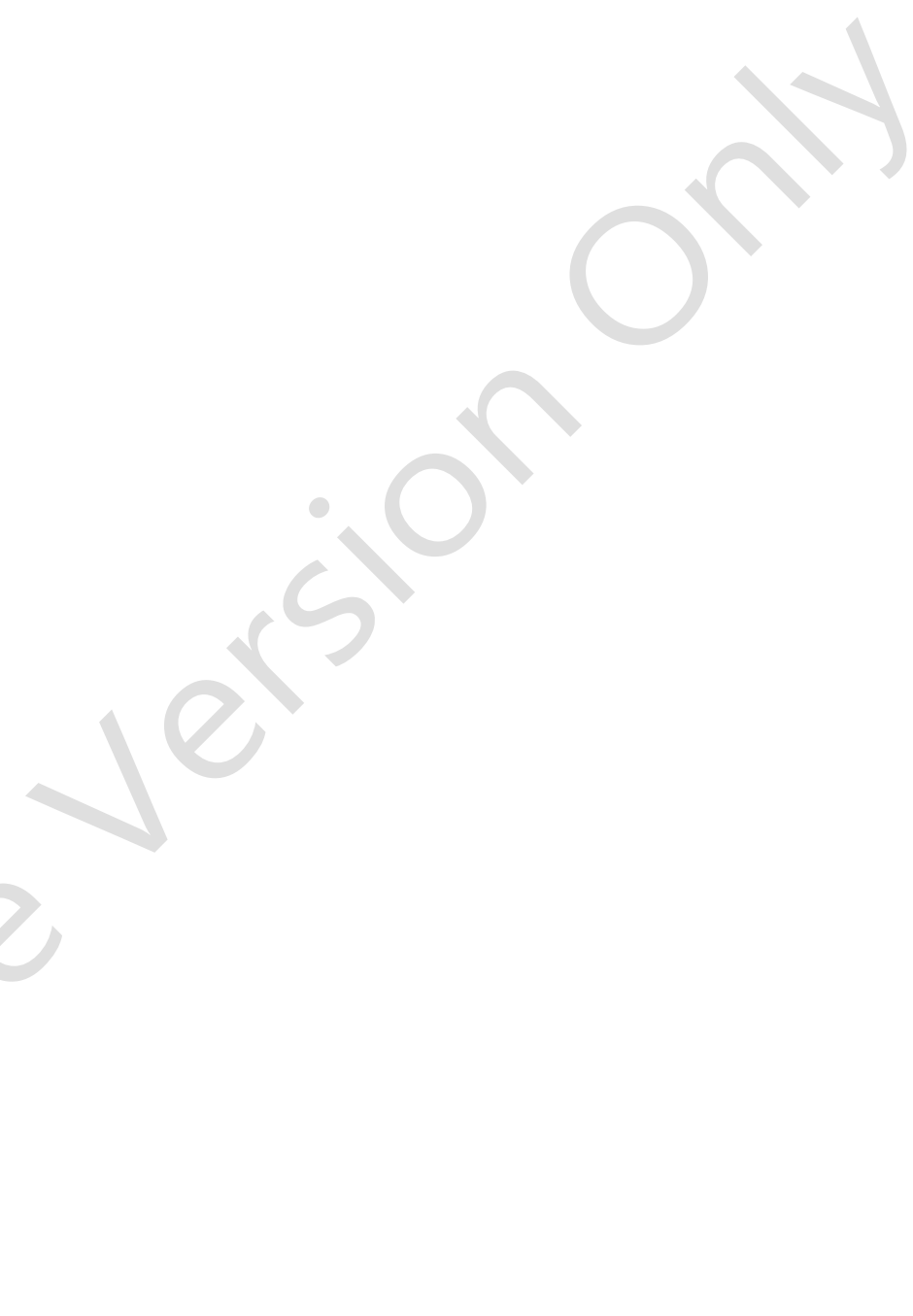

